\title{
Tobacco and electronic cigarette cues for smoking and vaping: an online experimental study
}

\author{
Anna K. M. Blackwell ${ }^{1 *}\left(\mathbb{D}\right.$, Katie De-loyde ${ }^{1}$, Laura A. Brocklebank1, Olivia M. Maynard', Theresa M. Marteau², \\ Gareth J. Hollands' , Paul C. Fletcher ${ }^{3,4}$, Angela S. Attwood' ${ }^{1}$, Richard W. Morris ${ }^{5}$ and Marcus R. Munafò 1,6
}

\begin{abstract}
Objective: This study examined whether exposure to smoking and vaping cues the urge to smoke or vape. It extends previous studies on first-generation cigalikes (visually similar to cigarettes) and second-generation devices (visually similar to pens) by including third-generation tank system devices (larger bulky units). In an online experiment, participants were randomly assigned to view one of four videos, which included smoking, vaping (cigalike or tank system), or neutral cues. The primary outcome was urge to smoke. Secondary outcomes were urge to vape, desire to smoke and vape, and intention to quit or remain abstinent from smoking.

Results: UK adults varying in smoking (current or former) and vaping (user or non-user) status ( $n=1120$ ) completed the study: 184 (16\%) failed study attention checks meaning 936 were included in the final analysis. Urges to smoke were similar across cue groups. Urges to vape were higher following exposure to vaping compared to neutral cues. There was no clear evidence of an interaction between cue group and smoking or vaping status. The lack of cueing effects on smoking urges is inconsistent with previous research, raising questions about the ability to assess craving in online settings.
\end{abstract}

Keywords: Smoking, Cigarette, Vaping, E-cigarette, Cue reactivity, Public health, Policy

\section{Introduction}

The impact of e-cigarette use (vaping) is debated within global public health communities; there is evidence that it is an effective smoking cessation aid [1,2], but there are also concerns around potential risks, including renormalisation of smoking [3]. In the UK, approximately $6 \%$ of adults (age 16+) vape [4]. Public Health England (PHE) support e-cigarette use for smoking cessation [5], which is recommended as part of the National Health Service (NHS) smoke-free advice [6]. E-cigarettes are not included in the Health Act 2006, which bans smoking in

\footnotetext{
*Correspondence: anna.blackwell@bristol.ac.uk

${ }^{1}$ School of Psychological Science, University of Bristol, 12a Priory Road, Bristol BS8 1TU, UK

Full list of author information is available at the end of the article
}

public places; however, organisations often include them alongside cigarettes within smoking policies. There is also variability across organisations regarding the availability of shared or separate spaces for smokers and vapers [7].

The impact of differences in available spaces on smokers and vapers is unknown. Exposure to smoking or vaping cues has the potential to increase smoking or vaping urges, which is particularly concerning for former- or non-users in public areas. In shared spaces, exposure to smoking cues could increase smoking urges, or reduce vaping urges, among former smokers and those trying to quit through vaping, undermining smoking abstinence. It is also possible that exposure to vaping in shared spaces could cue vaping urges in smokers, increasing the desire to reduce or quit smoking through vaping. 
Previous research on the impact of vaping cues has focussed on cross-cueing effects. For example, passive exposure to first-generation cigalike e-cigarettes (visually similar to cigarettes) can increase desire to vape and smoke, whereas exposure to tobacco cigarettes may only increase desire to smoke [8]. Similarly, second-generation e-cigarettes (size and shape of a large pen) can cue smoking urges among young adult daily and non-daily smokers [9]. The impact of newer third-generation e-cigarettes is currently unknown.

We aimed to directly compare the impact of viewing different e-cigarette cues (including first-generation cigalikes and third-generation tank systems, which are larger, bulky devices), to tobacco smoking or neutral cues among people with different smoking and vaping backgrounds. We hypothesised that smoking urges following exposure to vaping cues would be higher relative to neutral cues and lower relative to smoking cues, and that smoking urges would be lower following exposure to tank system vape cues relative to cigalike cues.

\section{Main text \\ Methods \\ Study design}

This online study used a between-subjects design. Participants were allocated to one of four stimulus groups (cigalike, tank system, tobacco cigarette, neutral) according to their smoking and vaping status (i. dual user: current smoker and vaper, ii. smoker: current smoker, non-vaper, iii. vaper: current vaper, former smoker, iv. non-user, former smoker, non-vaper). Participants were randomised to view one of four video cues [10-13]. Each video showed two individuals talking with one shown: i. vaping using a cigalike; ii. vaping using a tank system, iii. smoking a tobacco cigarette, or iv. moving their hand to their mouth without smoking or vaping (neutral). The primary outcome measure was post-intervention self-reported craving for tobacco cigarettes (smoking urge). Secondary outcomes were post-intervention self-reported craving for e-cigarettes (vaping urge), post-intervention desire for a cigarette and e-cigarette, intention to quit tobacco smoking (current smokers), and self-efficacy to remain abstinent from smoking (former smokers).

\section{Participants}

The study was hosted on the Qualtrics online survey platform [14]. Participants were UK adults ( $18+$ years) who were either: current smokers (smoke $\geq 5$ cigarettes a day for at least one year, not trying to quit) or former smokers (previously smoked $\geq 5$ cigarettes a day for at least one year) and were either vapers (vape daily), or non-vapers (vaped $\leq 20$ times). They were recruited through the
Prolific crowdsourcing platform [15], which advertised the study to its members based on pre-specified screening questions. The study took approximately $10 \mathrm{~min}$ and participants were reimbursed $£ 1$ through their account.

\section{Measures}

Self-reported craving for tobacco was measured pre- and post-intervention using the brief questionnaire of smoking urges (QSU-Brief) [16, 17], with a modified version used to assess self-reported craving for e-cigarettes [18], on a scale of 10 (strongly disagree) to 70 (strongly agree). Desire for a cigarette and e-cigarette were collected preand post-intervention on a visual analogue scale (VAS) of $0-100$. The following questions assessed intention to quit smoking or self-efficacy to remain abstinent: 'Are you planning to quit smoking within the next 6 months?' [19], 'How confident are you that you will remain a nonsmoker?' [20], using scales of 1 (low) to 5 (high).

\section{Procedure}

Participants who expressed an interest were shown an information statement explaining the study. They were told the purpose was to provide feedback on videos for future research, to avoid them paying undue attention to their desire to smoke or vape. Participants willing to continue completed a tick box consent page. Participants then completed screening and demographic questions, baseline ratings of smoking and vaping craving, alongside filler questions. They then viewed one of four one-min cue videos according to their condition, followed by video-related cover questions and questions on craving and intention to quit smoking or remain abstinent. Finally, participants were asked what they thought the purpose was of the study. Attention check questions were embedded within the questions and participants who failed these were excluded post-randomisation and replaced to ensure high data quality. At the end of the study, participants were provided with debriefing information and contact details of the research team.

\section{Data analysis}

Two-way ANCOVAs were used to assess the impact of exposure to video cues (cigalike, tank system, cigarette, neutral) on: i. post-intervention smoking and vaping urge scores, and ii. post-intervention desire for a cigarette and e-cigarette scores, for the four smoking and vaping status groups (dual-user, smoker, vaper, non-user), using pre-intervention score as a covariate. Two-way ANOVAs were used to assess the impact of video cue on secondary outcomes (intention to quit or remain abstinent) for the four smoking and vaping status groups. 
Table 1 Demographic, smoking and vaping characteristics of experimental groups $(n=936)$

\begin{tabular}{|c|c|c|c|c|}
\hline & \multicolumn{4}{|c|}{ Experimental groups $\mathbf{n}(\%)^{\mathbf{a}}$} \\
\hline & Cigalike $(n=226)$ & Tank system $(n=232)$ & Cigarette $(n=242)$ & Neutral $(n=236)$ \\
\hline Age ( $M, S D$, range) & $40(12) 19-75$ & 39 (13) 19-72 & 38 (11) 19-70 & 38 (10) 20-67 \\
\hline \multicolumn{5}{|l|}{ Gender } \\
\hline Male & $71(31)$ & $90(39)$ & $86(36)$ & $81(34)$ \\
\hline Female & $155(69)$ & $142(61)$ & $156(64)$ & $155(66)$ \\
\hline \multicolumn{5}{|l|}{ Education } \\
\hline Higher education or professional & $102(45)$ & $112(48)$ & $117(48)$ & $116(49)$ \\
\hline A levels or equivalent & $66(29)$ & $64(28)$ & $66(27)$ & $61(26)$ \\
\hline GCSE/O level grade $A^{*}-C$, or equivalent & $47(21)$ & $52(22)$ & $47(19)$ & $43(18)$ \\
\hline Qualifications at level 1 and below & $3(1)$ & $1(<1)$ & $3(1)$ & $7(3)$ \\
\hline Other qualifications: level unknown & $7(3)$ & 0 & $4(2)$ & $4(2)$ \\
\hline No qualifications & $1(<1)$ & $3(1)$ & $5(2)$ & $5(2)$ \\
\hline \multicolumn{5}{|l|}{ Smoking and vaping status } \\
\hline Dual users & $23(10)$ & $28(12)$ & $20(8)$ & $25(11)$ \\
\hline Smokers only & $67(30)$ & $68(29)$ & $71(29)$ & $72(31)$ \\
\hline Vapers only & $66(29)$ & $68(29)$ & $76(31)$ & $72(31)$ \\
\hline Non-users & $70(31)$ & $68(29)$ & $75(31)$ & $67(28)$ \\
\hline
\end{tabular}

a Unless otherwise stated

Further details of the study methods, materials, additional measures and statistical analysis plan can be found in the preregistered study protocol [21].

\section{Results}

A total of 1120 participants completed the study. 184 (16\%) failed attention checks and were excluded postrandomisation, ${ }^{1}$ meaning 936 participants were included in the final analysis (see Table 1 for demographic characteristics).

\section{Smoking and vaping urges}

There was no clear evidence of an interaction effect between video cue group and smoking and vaping status group for either ANCOVA models: smoking urge $(\mathrm{F}[9919]=1.63, \mathrm{p}=0.10)$ and vaping urge $(\mathrm{F}[9919]=0.66$, $\mathrm{p}=0.75$ ). Therefore, the interaction was dropped from the model in favour of a single model to estimate main effects with greater precision.

There was no clear evidence of a main effect between the four video cue groups on smoking urge ( $\mathrm{F}[3$, $928]=1.33, \mathrm{p}=0.26$ ): there was no evidence of a difference in smoking urge between: $i$. vaping cues (combined)

\footnotetext{
${ }^{1}$ A higher number of non-vapers (smokers $=79$, non-users $=73$ ) were excluded compared to vapers (vapers $=13$, dual-users $=19$ ). This difference may at least partly reflect the placement of the second attention question within a series of vaping-related questions. Future studies should embed attention questions within neutral questions in which levels of attention would be expected to be similar across groups.
}

and neutral cue (mean difference $[\mathrm{MD}]=0.05,95 \% \mathrm{CI}$ $0.89-0.98, \mathrm{p}=0.92$ ), ii. vaping cues (combined) and smoking cue $(\mathrm{MD}=0.9,95 \% \mathrm{CI} 0.03-1.83, \mathrm{p}=0.06)$, or iii. cigalike and tank system vaping cues $(\mathrm{MD}=0.1,95 \%$ CI $0.99-1.20, \mathrm{p}=0.85)($ Table 2).

There was strong evidence of a main effect between the video cue groups on vaping urge $(F[3928]=6.66$, $\mathrm{p}<0.001)$ : urges were higher following exposure to both cigalike ( $\mathrm{MD}=1.8,95 \% \mathrm{CI} 0.4-3.2, \mathrm{p}=0.005)$ and tank system vaping $(\mathrm{MD}=2.1,95 \% \mathrm{CI} 0.7-3.5, \mathrm{p}<0.001)$ cues compared to the neutral cue (Table 2).

\section{Desire to smoke and vape}

There was no clear evidence of a main effect between the four video cue groups on desire to smoke $(\mathrm{F}[3928]=1.58$, $\mathrm{p}=0.19)$ and weak evidence of a difference on desire to vape $(F[3928]=2.43, p=0.06)$, which was higher following exposure to cigalike $(\mathrm{MD}=3.0,95 \% \mathrm{CI} 0.6-5.4$, $\mathrm{p}=0.02)$ and tank system ( $\mathrm{MD}=2.7,95 \%$ CI $0.3-5.1$, $\mathrm{p}=0.03)$ cues compared to the neutral cue (Table 2).

\section{Intention to quit or remain abstinent}

There was no evidence of a main effect of video cue groups on intention to quit smoking $(\mathrm{F}[3369]=1.33$, $\mathrm{p}=0.27$ ). There was weak evidence of a main effect of video groups on intention to remain abstinent from smoking $(\mathrm{F}[3557]=3.034, \mathrm{p}=0.03)$, which was higher following exposure to the cigarette cue compared to the neutral cue $(\mathrm{MD}=0.3,95 \% \mathrm{CI} 0.03-0.6, \mathrm{p}=0.02)$ (Table 2). 
Table 2 Primary and secondary outcomes- adjusted

\begin{tabular}{|c|c|c|c|c|}
\hline \multirow[t]{2}{*}{ Cue type } & \multicolumn{4}{|c|}{ Experimental groups $\mathrm{M}(95 \% \mathrm{Cls})$} \\
\hline & Cigalike & Tank system & Cigarette & Neutral \\
\hline Urge to smoke $e^{a}$ & $25.7(24.9,26.5)$ & $25.8(25.0,26.6)$ & $26.6(25.9,27.4)$ & $25.8(25.0,26.6)$ \\
\hline Urge to vape ${ }^{a}$ & $25.2(24.4,25.9)$ & $25.5(24.7,26.2)$ & $24.1(23.4,24.9)$ & $23.4(22.6,24.1)$ \\
\hline Desire for a cigarette ${ }^{b}$ & $28.7(26.6,30.7)$ & $28.9(26.9,30.9)$ & $31.2(29.2,33.3)$ & $28.7(26.6,30.7)$ \\
\hline Desire for an e-cigarette ${ }^{b}$ & $26.6(24.8,28.4)$ & $26.3(24.6,28.1)$ & $25.1(23.3,26.8)$ & $23.6(21.9,25.4)$ \\
\hline Intention to quit smoking ${ }^{c}$ & $2.7(2.4,2.9)$ & $2.9(2.6,3.1)$ & $2.6(2.3,2.8)$ & $2.7(2.5,3.0)$ \\
\hline Likelihood remain abstinent $^{d}$ & $4.3(4.2,4.5)$ & $4.2(4.1,4.4)$ & $4.4(4.3,4.6)$ & $4.1(3.9,4.2)$ \\
\hline
\end{tabular}

a QSU (Questionnaire of smoking or vaping urges): 10 (minimum)-70 (maximum)

b Desire for a cigarette/e-cigarette: 0 (not at all)-100 (most ever)

c Intentions to quit smoking (current smokers): 1 (least)-5 (most)

d Likelihood to remain abstinent from smoking (ex-smokers): 1 (least)-5 (most)

The results remained unchanged when sensitivity analyses were conducted to remove participants who did not correctly identify the video cue $(n=88)$, or correctly identified the purpose of the study $(n=421)$.

The smoking and vaping urge and desire scores were heavily skewed towards the minimum scores (being 10 and 0 respectively), demonstrating possible floor effects. A comparison amongst video cue groups between those participants at floor or above found that the proportions were similar across groups.

\section{Discussion}

This online study found no evidence of a cross-cueing effect of exposure to vaping cues on smoking urges or exposure to smoking cues on vaping urges, or an interaction between cue exposure effects and smoking or vaping status. Similarly, there was no evidence of a cueing effect on participants' reported desire to smoke, or intention to quit smoking. There was some evidence of exposure to smoking, relative to neutral, cues increasing intention to remain abstinent in former smokers, and of vaping, relative to neutral, cues increasing vaping urges and desires.

The limited cueing effects on smoking urges were unexpected. One possibility is that previous studies have overestimated the impact on smoking urges of exposure to vaping or smoking cues; however, given differences in study methodology, it is more likely that the lack of effects reflect-at least in part-limitations of the materials and setting used in the current design. For example, King and colleagues [9] used confederate smokers or vapers, exposing participants to more ecologically valid cues compared to the videos used here.

Videos have been used in previous cue reactivity studies [22], and have the advantage of portraying contextual cues involved in typical, dynamically-represented smoking behaviour, although they only require participants to be passive observers [23]. In the present study the videos were specifically designed to show relatively neutral contexts, changing only the use of a cigarette, e-cigarette or neutral action, to control for confounding smoking cues (e.g., alcohol-related bar setting), which may have reduced their potential to elicit cravings. However, this study did find increased vaping urges following exposure to vaping video cues relative to neutral cues, which suggests the videos alone may not explain the lack of cueing effects on smoking urges.

It is possible that the online setting precluded control over other aspects of the environment in which participants completed the study, which could have influenced their responses. Both nicotine dependence and deprivation influence cue reactivity [24]. It is possible that these were both low among participants in the present study and that this reduced the likelihood of the videos cueing smoking and vaping urges. This explanation is consistent with the tendency towards floor effects found on the smoking and vaping scales of craving and desire. We did not measure nicotine dependence, and it was not possible to implement a minimum period of smoking or vaping abstinence before starting the study in the online setting; therefore, it is not possible to explore this further.

\section{Conclusions}

The current study found no evidence that exposure to videos of smoking or vaping cued smoking urges and no evidence of interaction effects between cue exposure and smoking and vaping status. These findings may be explained as a consequence of using video cues with neutral contexts within an online setting, which allowed for minimal control over participants' recent smoking or vaping activity. Future studies should exercise caution when using an artificial setting to assess craving. 


\section{Limitations}

- Using videos of smoking or vaping behaviour with limited contextual details may have been insufficient to elicit smoking cravings.

- It was not possible to control for a minimum period of smoking or vaping abstinence in the online setting.

- We did not measure nicotine dependence which could have influenced cue reactivity.

\begin{abstract}
Abbreviations
e-cigarette: electronic cigarette; UK: United Kingdom; PHE: Public Health England; NHS: National Health Service; ANCOVA: Analysis of Covariance; ANOVA: Analysis of Variance; QSU: questionnaire of smoking urges; VAS: visual analogue scale; M: mean; SD: standard deviation; A level: General Certificate of Education Advanced Level; O level: General Certificate of Education Ordinary Level; GCSE: General Certificate of Secondary Education; MD: mean difference; Cl: confidence interval.
\end{abstract}

\section{Acknowledgements}

The authors would like to thank Prolific staff who assisted with setting up the online study.

\section{Authors' contributions}

$A K M B, L A B, O M M, T M M, G J H, P C F, A S A, K D L, R M$ and MRM contributed to the conception and design of the study and the study protocol. AKMB managed the day-to-day running of the study. KDL and RM conducted data analysis and all authors helped with data interpretation. This manuscript was written by AKMB with input from all co-authors. All authors read and approved the final manuscript.

\section{Funding}

This research was funded by a Collaborative Award in Science from the Wellcome Trust (Behaviour Change by Design: 206853/Z/17/Z) awarded to Theresa Marteau, Paul Fletcher, Gareth Hollands and Marcus Munafò. The funder is not involved in the study design or data analysis.

\section{Availability of data and materials}

The anonymised data collected are available as open data via the University of Bristol online data repository [https://doi.org/10.5523/bris.299889i8ysm0d21 dt3rz63nipg].

\section{Ethics approval and consent to participate}

Ethics approval was obtained from the Faculty of Science Research Ethics Committee at the University of Bristol (Ethics approval code: 68724). Participants received information and contact details of the study team at the start of the online study and given sufficient time to read the information, consider any implications, and raise any questions prior to deciding to participate. Participants were informed that they were free to withdraw at any time by closing their browser. Consent was then obtained by asking participants to confirm they had read a series of statements and provide final consent that they were happy to continue before starting the study.

\section{Consent for publication}

Not applicable.

\section{Competing interests}

The authors declare that they have no competing interests.

\section{Author details}

${ }^{1}$ School of Psychological Science, University of Bristol, 12a Priory Road, Bristol BS8 1TU, UK. ${ }^{2}$ Behaviour and Health Research Unit, University of Cambridge, Cambridge CB2 0SR, UK. ${ }^{3}$ Department of Psychiatry, Cambridgeshire and Peterborough NHS Foundation Trust, University of Cambridge, Douglas
House, Cambridge CB2 8AH, UK. ${ }^{4}$ The Wellcome-MRC Institute of Metabolic Science-Metabolic Research Laboratories (IMS-MRL), University of Cambridge, Cambridge CB2 0QQ, UK. ${ }^{5}$ Bristol Medical School: Population Health Sciences, Canynge Hall, 39 Whatley Road, Bristol BS8 2PS, UK. ${ }^{6}$ MRC Integrative Epidemiology Unit (IEU), University of Bristol, Oakfield House Oakfield Grove, Bristol BS8 2BN, UK.

Received: 31 October 2019 Accepted: 8 January 2020

Published online: 15 January 2020

\section{References}

1. Adkison SE, O'Connor RJ, Bansal-Travers M, Hyland A, Borland R, Yong $\mathrm{H}-\mathrm{H}$, et al. Electronic nicotine delivery systems. Am J Prev Med. 2013;44(3):207-15

2. Hajek P, Phillips-Waller A, Przulj D, Pesola F, Myers Smith K, Bisal N, et al. A randomized trial of e-cigarettes versus nicotine-replacement therapy. $\mathrm{N}$ Engl J Med. 2019;380(7):629-37.

3. Green SH, Bayer R, Fairchild AL. Evidence, policy, and e-cigarettes-will England reframe the debate? N Engl J Med. 2016;374(14):1301-3.

4. ONS. e-cigarette use in England: Office for National Statistics. $2019 \mathrm{https}$ ://www.ons.gov.uk/peoplepopulationandcommunity/healthandsocial care/healthandlifeexpectancies/datasets/ecigaretteuseinengland.

5. McNeill A, Brose LS, Calder R, Bauld L, Robson D. Vaping in England: an evidence update February 2019. A report commissioned by Public Health England London, UK: Public Health England. 2019 https://www.gov.uk/ government/publications/vaping-in-england-an-evidence-update-Febru ary-2019.

6. NHS. Smokefree: e-cigarettes UK: National Health Service. 2018 https:// www.nhs.uk/smokefree/help-and-advice/e-cigarettes.

7. Blackwell AKM, Kosite D, Marteau T, Munafo MR. Policies for tobacco and e-cigarette use: a survey of all higher education institutions and NHS trusts in England. Nicotine Tob Res. 2019. https://doi.org/10.1093/ntr/ ntz192.

8. King AC, Smith LJ, McNamara PJ, Matthews AK, Fridberg DJ. Passive exposure to electronic cigarette (e-cigarette) use increases desire for combustible and e-cigarettes in young adult smokers. Tob Control. 2014. https://doi.org/10.1136/tobaccocontrol-2014-051563.

9. King AC, Smith LJ, McNamara PJ, Cao D. Second generation electronic nicotine delivery system vape pen exposure generalizes as a smoking cue. Nicotine Tob Res. 2017. https://doi.org/10.1093/ntr/ntw327.

10. TARG Bristol. Cigalike cue video 2018. https://youtu.be/ffnHviXTwKk.

11. TARG Bristol. Tank system cue video 2018. https://youtu.be/UMiSkYyHXG E.

12. TARG Bristol. Tobacco cigarette cue video. 2018. https://youtu.be/ob8S08NVyo.

13. TARG Bristol. Neutral cue video. 2018 https://youtu.be/lxjuCY2dL2Q

14. Qualtrics Online Survey Software: Qualtrics. 2019. https://www.qualtrics. com/uk/core-xm/survey-software/.

15. Prolific. Prolific. 2019 https://www.prolific.co/.

16. Tiffany ST, Drobes DJ. The development and initial validation of a questionnaire on smoking urges. Br J Addict. 1991:86(11):1467-76.

17. Cox LS, Tiffany ST, Christen AG. Evaluation of the brief questionnaire of smoking urges (QSU-brief) in laboratory and clinical settings. Nicotine Tob Res. 2001;3(1):7-16.

18. St. Helen G, Havel C, Dempsey DA, Jacob P, Benowitz NL. Nicotine delivery, retention and pharmacokinetics from various electronic cigarettes. Addiction. 2016;111(3):535-44.

19. Hummel K, Candel MJJM, Nagelhout GE, Brown J, van den Putte B, Kotz $D$, et al. Construct and predictive validity of three measures of intention to quit smoking: findings from the International Tobacco Control (ITC) Netherlands Survey. Nicotine Tob Res. 2017. https://doi.org/10.1093/ntr/ ntx092.

20. International Tobacco Control (ITC) Policy Evaluation Project. 4-Country W4 Recontact Survey Code: 4C4-C Ontario: Canada: International Tobacco Control (ITC) Policy Evaluation Project, Department of Psychology, University of Waterloo. http://www.itcproject.org/files/TC_4C4_ Recontact_SQ_tel_Eng.pdf. 
21. Blackwell AKM, Brocklebank LA, Maynard OM, Marteau TM, Hollands GJ, Fletcher PC, et al. Availability of shared vs separate places for Tobacco and e-cigarette Use: Study 1: OSF; 2019 [Available from: osf.io/a6jpu.]

22. Tong C, Bovbjerg DH, Erblich J. Smoking — related videos for use in cueinduced craving paradigms. Addict Behav. 2007;32(12):3034-44.

23. Pericot-Valverde I, Germeroth LJ, Tiffany ST. The use of virtual reality in the production of cue-specific craving for cigarettes: a meta-analysis. Nicotine Tob Res. 2015;18(5):538-46.
24. Payne TJ, Smith PO, Sturges LV, Holleran SA. Reactivity to smoking cues: mediating roles of nicotine dependence and duration of deprivation. Addict Behav. 1996:21(2):139-54.

\section{Publisher's Note}

Springer Nature remains neutral with regard to jurisdictional claims in published maps and institutional affiliations.
Ready to submit your research? Choose BMC and benefit from:

- fast, convenient online submission

- thorough peer review by experienced researchers in your field

- rapid publication on acceptance

- support for research data, including large and complex data types

- gold Open Access which fosters wider collaboration and increased citations

- maximum visibility for your research: over 100M website views per year

At BMC, research is always in progress.

Learn more biomedcentral.com/submissions 